\title{
A potential protective effect of a-tocopherol on vascular complication in spinal cord reperfusion injury in rats
}

\author{
Mohamed D Morsy*1, Ossama A Mostafa ${ }^{2}$ and Waleed N Hassan ${ }^{3}$
}

\begin{abstract}
Background: Paraplegia remains a potential complication of spinal cord ischemic reperfusion injury (IRI) in which oxidative stress induced cyclooxygenase activities may contribute to ischemic neuronal damage. Prolonged administration of vitamin $\mathrm{E}$ ( $\mathrm{a}-\mathrm{TOL}$ ), as a potent biological antioxidant, may have a protective role in this oxidative inflammatory ischemic cascade to reduce the incidence of paraplegia. The present study was designed to evaluate the preventive value of a-TOL in IRI of spinal cord.

Methods: For this study, 50 male Sprague-Dawley rats were used and divided into five experimental groups $(n=10)$ : Control group (C); a-TOL control group (CE) which received intramuscular (i.m.) a-TOL injections (600 mg/kg); Sham operated group (S), IRI rats were subjected to laparotomy and clamping of the aorta just above the bifurcation for 45 $\mathrm{min}$, then the clamp was released for $48 \mathrm{hrs}$ for reperfusion; and IRIE rats group, received $600 \mathrm{mg} / \mathrm{kg}$ of a-TOL i.m. twice weekly for 6 weeks, followed by induction of IRI similar to the IRI group. At the end of the experimental protocol; motor, sensory and placing/stepping reflex evaluation was done. Plasma nitrite/nitrate (NOx) was measured. Then animals' spinal cord lumbar segments were harvested and homogenized for measurement of the levels of prostaglandin $E_{2}$ $\left(\mathrm{PGE}_{2}\right)$, malondialdehyde (MDA) and advanced oxidation products (AOPP), while superoxide dismutase (SOD) and catalase (CAT) activity were evaluated.

Results: Induction of IRI in rats resulted in significant increases in plasma levels of nitrite/nitrate $(p<0.001)$ and spinal cord homogenate levels of $\mathrm{PGE}_{2}, \mathrm{MDA}$, advanced oxidation protein products $\mathrm{AOPP}$ and $\mathrm{SOD}$ with significant reduction $(p<0.001)$ in CAT homogenate levels. Significant impairment of motor, sensory functions and placing/stepping reflex was observed with IRI induction in the spinal cord $(p<0.001)$. a-TOL administration in IRIE group significantly improved all the previously measured parameters compared with IRI group.
\end{abstract}

Conclusions: $\mathrm{a}-\mathrm{TOL}$ administration significantly prevents the damage caused by spinal cord IRI in rats with subsequent recovery of both motor and sensory functions. Alpha-tocopherol improves the oxidative stress level with subsequent reduction of the incidence of neurological deficits due to spinal cord IRI conditions.

\section{Background}

Ischemic reperfusion injury (IRI) of the spinal cord occurs due to temporary interruption of the blood supply to the spinal cord. This may result in irreversible vascular injuries with subsequent paraplegia or other neurological deficits [1]. This serious complication is frequently seen in transient ischemic insults of the spinal cord and after surgical repair of thoraco-abdominal aortic aneurysms

* Correspondence: morsydarwesh@yahoo.com

1 Physiology Department, College of Medicine, Menoufiya University, Egypt Full list of author information is available at the end of the article
[2]. Oxidative stress with over-production of reactive oxygen species (ROS), such as free radicals and peroxides are incriminated in the neurological vascular injuries [3]. Increased ROS in dorsal horn neurons may contribute to central sensitization in neuropathic rats [4]. Overproduction of ROS and oxygen free radicals in ischemic reperfusion conditions may also lead to excessive lipid peroxidation and protein and DNA damage [5]. In rats, with ligation of sciatic nerve, superoxide dismutase (SOD) and glutathione peroxidase (GPx) activities increase, while catalase (CAT) activity decrease signifi- 
cantly due to associated oxidative stress and reduction of antioxidant defense potential [6]. In addition, Regan and Guo [7] reported that prolonged depletion of glutathione in the brain is associated with oxidative neuronal death. Ischemia induces oxidative stress, leading to induction and expression of various genes in a variety of cell types throughout the central nervous system [8]. One of these important genes is the cyclooxygenase enzyme gene. This enzyme is the rate-limiting enzyme involved in arachidonic acid metabolism, with subsequent generation of prostaglandins and thromboxanes that play important roles in sustaining the inflammatory response and induce different neurological deficits [9]. Elements of oxidative stress appeared to be essential for the activation of this enzyme [10]. Oxidative stress induces cyclooxygenase-2 (COX-2) activity in neurons after various CNS insults, including global ischemia [11].

The COX-2 inhibitors as SC-58125 and NS-398 have been shown to prevent delayed death of hippocampal neurons [12] and to reduce infarct size after global ischemia [13]. Vitamin E ( $\alpha$-tocopherol) is an important lipidsoluble chain-breaking antioxidant, essential to scavenge ROS in tissues, red cells, and plasma [14]. $\alpha$-tocopherol $(\alpha-\mathrm{TOL})$ significantly reduces induced nitric oxide synthase enzyme (iNOS) activity and cyclic glutamate monophosphate (cGMP) levels in diabetic rats [15]. $\alpha$-TOL, which is the predominant form of vitamin $\mathrm{E}$ in clinical uses, has been found to attenuate COX-2 activity by scavenging the oxidant hydroperoxide that acts as activator for COX-2 enzyme with subsequent suppression of prostaglandin $\mathrm{E}_{2}\left(\mathrm{PGE}_{2}\right)$ production [16]. Other experiments demonstrated that $\alpha$-TOL decreases COX-2 activity through reduction of peroxynitrite formation necessary for its activation [17]. Another mechanism through which $\alpha$-TOL reduces PGE $_{2}$ production could be through direct inhibition of COX activity without affecting COX mRNA and its protein levels, indicating a post-translational regulation of COX [18].

Most of the carried studies in this field were constructed for short-term administration of the therapeutic agents just before or after IRI, while our study could be one of the recent studies for long-term prophylactic administration of $\alpha$-TOL on IRI of the spinal cord.

So, the aim of the present study is to explore the possible prophylactic effect of long-term administration of $\alpha$ TOL in spinal cord reperfusion injury against high oxidative stress induced by ischemia; and to investigate the role of $\alpha$-TOL in the inhibition of COX-2 activity, with subsequent suppression of inflammatory $\mathrm{PGE}_{2}$ over-production.

\section{Methods}

\section{Animals and their groups}

This study followed a randomized controlled animal experiment design. A total of 50 male Sprague-Dawley rats were randomized into 5 study groups. All rats were obtained from the National Research Center, Cairo, Egypt and weighed between 150 and 200 gm. Animals were fed on a standard chow diet, water, ad libitum and housed in the animal house of Menoufiya College of Medicine with a 12:12-hrs light/dark cycle. The animals were randomly divided into five groups $(\mathrm{n}=10$ each) as follows: $\mathrm{C}$ rats which underwent no surgery; $\mathrm{CE}$ animals received $\alpha$-TOL $600 \mathrm{mg} / \mathrm{kg}$ i.m. twice weekly [19]; S (sham) rats were subjected to laparotomy without clamping of the aorta; IRI rats were subjected to laparotomy and clamping the aorta by non-traumatic vascular clamp just above the bifurcation for $45 \mathrm{~min}$, then the clamp was released for reperfusion for $48 \mathrm{hrs;}$ and IRIE rats were injected i.m. with $\alpha$-TOL by the same dose and maneuver as rats in the CE group then IRI was induced as in IRI group. Control rats were injected i.m. with vehicle alone. The experiments were conducted in accordance with the ethical guidelines for investigations in laboratory animals and were approved by the Ethical Committee of the College of Medicine, Menoufiya University.

\section{Induction of ischemic reperfusion injury of the spinal cord}

Spinal cord ischemia was induced, as described by Akguna et al. [20]. Rats were initially anesthetized with i.m. ketamine $(50 \mathrm{mg} / \mathrm{kg})$, followed by a half dose as required during the procedure. The animals did not receive ventilatory support. Body temperature was monitored by a rectal probe inserted into the rectum and was maintained between $37^{\circ} \mathrm{C}$ and $38^{\circ} \mathrm{C}$ by a thermal pad and a heating lamp. The femoral artery was cannulated with a 22-gauge PE catheter, which was used to monitor distal arterial pressure (DAP) and for intra-arterial infusion of heparin. The left carotid artery was cannulated with a 20gauge PE catheter (Terumo, Tokyo, Japan), which was used to monitor the proximal artery pressure (PAP) and to take blood samples. Each rat received $150 \mathrm{IU} / \mathrm{kg}$ heparin injected into the femoral artery immediately after completion of arterial cannulation and before aortic occlusion. The abdominal aorta was reached through midline laparotomy. Animals in sham group (group S) were anesthetized and subjected to laparotomy without aortic occlusion. In IRI and IRIE groups, animals were subjected to aortic cross clamping for 45 minutes. Vascular clamps were placed under the left renal vein and above the bifurcation of the aorta. The efficiency of occlusion was documented by an immediate and sustained decrease in DAP in the femoral artery. To maintain the PAP approximately at $40 \mathrm{mmHg}$ during occlusion, blood from the carotid artery was allowed to flow into a collecting circuit filled with heparinized saline ( $4 \mathrm{U} / \mathrm{ml}$ of saline) positioned $54 \mathrm{~cm}$ above the rat. The temperature of the blood in the syringe was maintained at $37-37.5^{\circ} \mathrm{C}$. The aortic clamps were released after $45 \mathrm{~min}$ and the blood in the syringe was transfused back into the rat over a $60-\mathrm{sec}$ 
period. After completion of all procedures, the wounds were closed. Protamine sulfate $(4 \mathrm{mg})$ was subcutaneously injected to reverse the anticoagulation effect of heparin. Animals were allowed to recover in a plastic box at $28^{\circ} \mathrm{C}$ for 3 hours and were then placed in their cages with free access to food and water [21]. Rats with complete hind limb paralysis for 24 hours, hematuria, or $25 \%$ reduction in body weight were killed by using a lethal dose of thiopental sodium injection ( $75 \mathrm{mg} / \mathrm{kg}$ i.p.) for humanitarian reasons [22].

\section{Neurological assessment}

Hind limbs neurologic function was assessed at 48 hours after the procedure using the Tarlov Scoring System [23]. A score of 0-5 was assigned to each animal as follows: $0=$ no voluntary hind limb movement; 1 = movement of joints perceptible; 2 = active movement but unable to sit without assistance; 3 = able to sit but unable to hop; $4=$ weak hop; 5 = complete recovery of hind limb function. The placing/stepping reflex (SPR) was assessed by dragging the dorsum of the hind paw along the edge of a surface. This normally evokes a coordinating lifting and placing response which was graded as follows: $0=$ normal; 1 = weak; and 2 = no stepping [24]. Sensory function was assessed by a hind limb withdrawal from a stimulus ( 1 = withdrawal response to noxious stimulus applied to hind limbs and $0=$ no response to noxious stimulus). One member of the research team who was blinded to the treatment groups conducted all neurological tests.

\section{Blood sampling and biochemical measurements}

At the end of the experimental protocol period (48 hrs after IRI), retro-orbital blood samples were obtained through heparinized capillary tubes after overnight fasting. Samples were added to EDTA and were centrifuged at $1000 \mathrm{rpm}$ for $15 \mathrm{~min}$ for separation of plasma and were stored at $-80^{\circ} \mathrm{C}$ to assay total plasma nitrite/nitrate (NOx) level.

\section{Estimation of plasma Nitrite/Nitrate (NOx)}

The method for estimation of total nitrite/nitrate (NOx) level was based on the Griess reaction. Plasma nitrite/ nitrate levels were measured after enzymatic conversion of nitrate $\left(\mathrm{NO}_{3}\right)$ to nitrite $\left(\mathrm{NO}_{2}\right)$ by nitrate reductase in the presence of NADPH. The oxidation of the coenzyme was monitored by the decrease in absorbance at $540 \mathrm{~nm}$. Results were expressed as $\mu \mathrm{mol} / \mathrm{L}$ [25].

\section{Preparation of spinal cord homogenates}

After completing the neurological assessment and obtaining the blood samples, all rats were killed using the lethal dose of thiopental sodium injection [22]. Sections of the 3, 4, 5 lumbar segments of the spinal cord were harvested, dissected out, cute into small pieces and homogenized using an Omni tissue homogenizer (Omni international, Gainesville, VA, USA) [26]. Tissues were homogenized in ice-cold lyses buffer [0.1 M phosphate, $\mathrm{pH}$ 7.4, $1 \mathrm{mM}$ EDTA, $10 \mu \mathrm{M}$ indomethacin (Cayman Chemical, Ann Arbor, MI, USA)] using a tube pestle. Acetone was added $(2 \times$ sample volume), and samples were centrifuged at $1500 \times \mathrm{g}$ for $10 \mathrm{~min}$ at $4^{\circ} \mathrm{C}$. The supernatants were then stored at $-80^{\circ} \mathrm{C}$ [27].

Malondialdehyde (MDA),Advanced oxidation products (AOPP) levels, as well as SOD and CAT activities in Spinal cord homogenate

Lipid peroxidation was assessed by the measurement of secondary product MDA after precipitation of protein by addition of trichloroacetic acid then thiobarbituric acid (TBA) which reacted with MDA to form TBA reactive product, which was measured at $532 \mathrm{~nm}$. An MDA solution, freshly prepared by the hydrolysis of 1,1,3,3-tetramethoxy propane was used as a standard [28]. Determination of advanced AOPP (with characteristic absorbance at $340 \mathrm{~nm}$ ) was based on spectrophotometric method detection (Shimadzu Corporation, Kyoto, Japan, UV- 160A) with tissue homogenate diluted with PBS to $0.2-0.5 \mathrm{~g} / \mathrm{ml}$ [29]. SOD activity was assayed following the method of Kakkar et al. [30]. The sample containing $5 \mu \mathrm{g}$ protein was mixed with sodium pyrophosphate buffer, phenazine methosulphate (PMT) and nitro blue tetrazolium (NBT). The reaction was started by the addition of $\mathrm{NADH}$, incubated at $30^{\circ} \mathrm{C}$ and stopped by the addition of $1 \mathrm{ml}$ of glacial acetic acid. The absorbance of the chromogen formed was measured at $560 \mathrm{~nm}$. One unit of SOD activity is defined, as the enzyme concentration required to inhibit chromogen production by $50 \%$ in one minute per mg protein under the assay condition. CAT activity was measured in homogenate by the method of Bonaventura et al. [31]. $5 \mu \mathrm{g}$ proteins from the homogenate was mixed with $2 \mathrm{ml}$ of $7.5 \mathrm{mM} \mathrm{H}_{2} \mathrm{O}_{2}$ and a time scan was performed for $10 \mathrm{~min}$ at $240 \mathrm{~nm}$ at $25^{\circ} \mathrm{C}$. One unit of CAT activity is defined as the amount of enzyme decomposing $1 \mu \mathrm{mol}$ of $\mathrm{H}_{2} \mathrm{O}_{2}$ per minute per mg protein.

\section{Spinal cord homogenate $\mathrm{PGE}_{2}$ determination}

Tissue levels of $\mathrm{PGE}_{2}$ in the spinal cord were assayed using monoclonal enzyme immunoassay (EIA) kit. The EIA kit demonstrates sensitivity from 10 to $1000 \mathrm{pg} / \mathrm{ml}$ and demonstrates little cross reactivity between structurally related $\mathrm{PE}_{3}$ and $\mathrm{PE}_{1}$. Absorbance $(412 \mathrm{~nm})$ values of standards and samples were corrected by subtraction of the background value to correct for absorbance caused by nonspecific binding [32].

\section{Chemicals}

$\alpha$-tocopherol was supplied by Sigma (St Louis, MO, USA) that utilizes polyoxyl-35- Ricinusolle as an emulsifier; ketamine hydrochloride was supplied by Pfizer Pharmaceutical Company, Inc, USA; thiopental sodium was sup- 
plied by Biocheme, Austria; heparin (Leo, Ballerup, Denmark); Protamine sulfate (Leo, Ballerup, Denmark); Prostaglandin $\mathrm{E}_{2}$ EIA kit and indomethacin (Cayman Chemical, Ann Arbor, MI, USA) and nitrate reductase from Aspergillus (Sigma).

\section{Statistical analysis}

Data were expressed as frequency, percentage and mean \pm SD. Testing significance was performed using $X^{2}$ test and the one-way analysis of variance (ANOVA). Post-hoc Scheffe test was applied to identify the source of statistical significance. $\mathrm{P}$-values $<0.05$ were considered statistically significant.

\section{Results}

In control and sham groups, the administration of $\alpha$-TOL did not produce any significant changes in plasma nitrite/ nitrate or spinal cord homogenate of MDA, AOPP and $\mathrm{PGE}_{2}$ levels, in addition to SOD activity and CAT activity. However, in sham operated group $\mathrm{PGE}_{2}$ increased significantly compared with the control groups (C, CE) (Fig. 1, $2,3)$.

\section{Plasma nitrite/nitrate level}

Induction of IRI in rats produced significant elevation of plasma nitrite/nitrate level $(59.3 \pm 4.5)$ compared with the control groups $[\mathrm{C}(20 \pm 1.3), \mathrm{CE}(18.4 \pm 1.4)$ and $\mathrm{S}(21.5 \pm$ 1.5), $(\mathrm{P}<0.001)]$. On the other hand, i.m. administration of $\alpha$-TOL for 6 weeks resulted in significant reduction of the plasma nitrite/nitrate level compared with IRI group $(33.2 \pm 2.2)$ or control groups $(\mathrm{P}<0.001)$ (Fig. 1$)$.
Spinal cord homogenate levels of MDA, AOPP and PGE Lipid oxidative product MDA $(7.1 \pm 0.1)$, protein oxidative product AOPP $(7.7 \pm 0.5)$ and inflammatory product $\mathrm{PGE}_{2}(35.4 \pm 2.1)$ levels in spinal cord homogenate increased significantly in IRI group compared with the control groups $[C(3.4 \pm 0.4), C E(4.0 \pm 0.2)$ and $S(19.3 \pm$ $1.8),(\mathrm{P}<0.001)]$. While administration of $\alpha$-TOL produced significant reduction of the previously mentioned parameters compared to the IRI group [(4.3 \pm 0.4$),(3.8 \pm$ 0.2), (26.6 \pm 1.4$), \mathrm{p}<0.001$ ] (Fig. 1, 2).

\section{Spinal cord homogenate activity of SOD and CAT}

Induction of IRI in rats resulted in significant elevation of the SOD activity $(15.1 \pm 2.2)$ and significant reduction of CAT activity $(1.7 \pm 0.3)$ in the spinal cord homogenate compared with the control group $[(7.6 \pm 0.2)$ and $(4.5 \pm$ 0.8 ), respectively, $\mathrm{p}<0.001$ for both comparisons]. While, i.m. administration of $\alpha$-TOL produced a significant reduction in SOD $(8.1 \pm 1.0)$ and a significant increase in CAT $(3.5 \pm 0.4)$ activities compared with the IRI group (P $<0.001$ for both) (Fig. 1, 2).

\section{Motor, SPR and sensory assessment}

In the present study, rats in the IRI group showed acute flaccid paraplegia of the hind limbs up to 6 hours after reperfusion injury followed by spastic paraplegia. Their motor score (mean $\pm \mathrm{SD}$ ) was $1.2 \pm 1.0$ compared with 4.8 \pm 0.4 in the control group. Also, sensory function was impaired in $80 \%$ of rats in the IRI group, while SPR was lost in $60 \%$ and was impaired in $20 \%$ of IRI rats. On the other hand, $\alpha$-TOL administration in IRIE group pro-

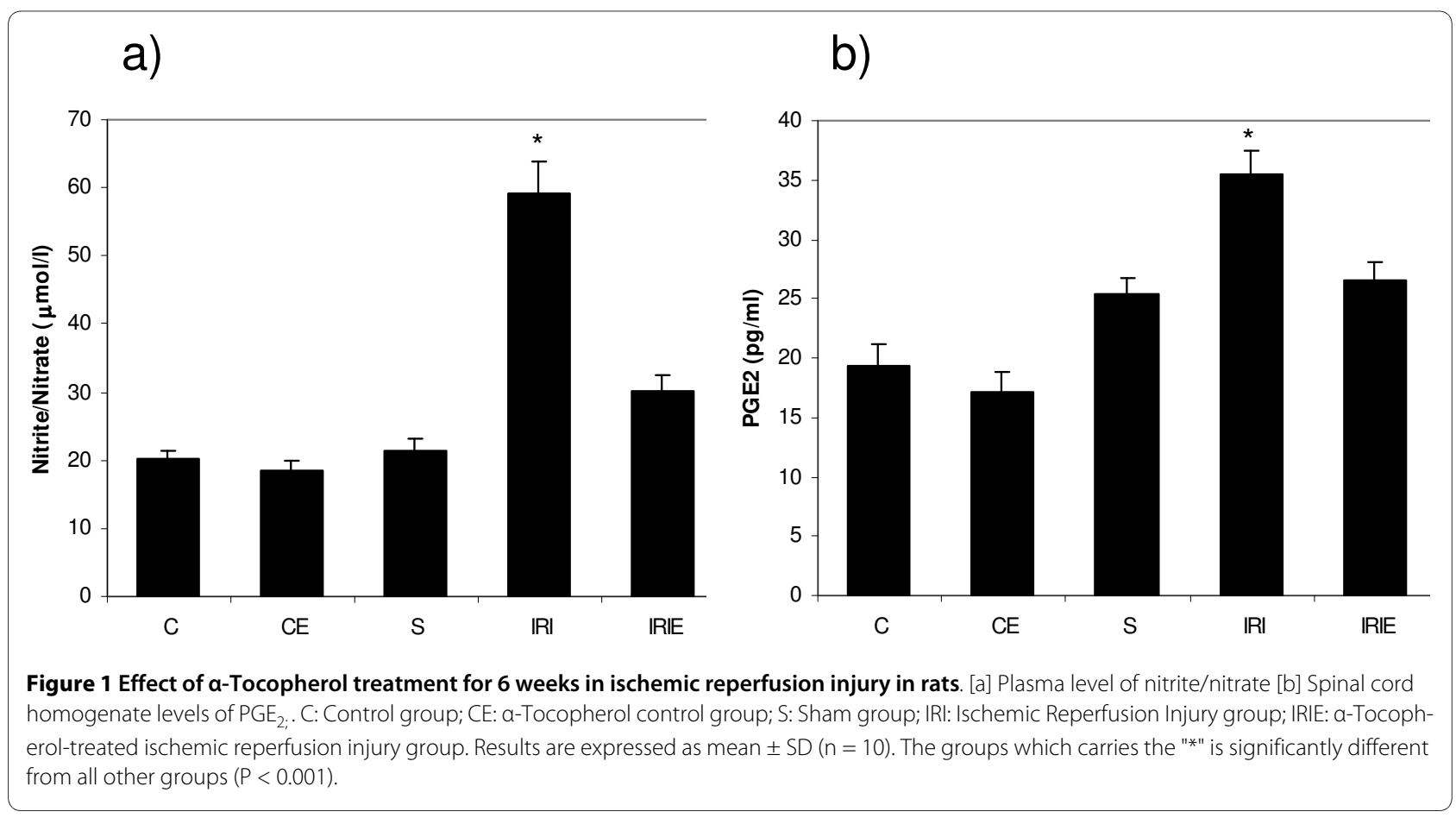


a)

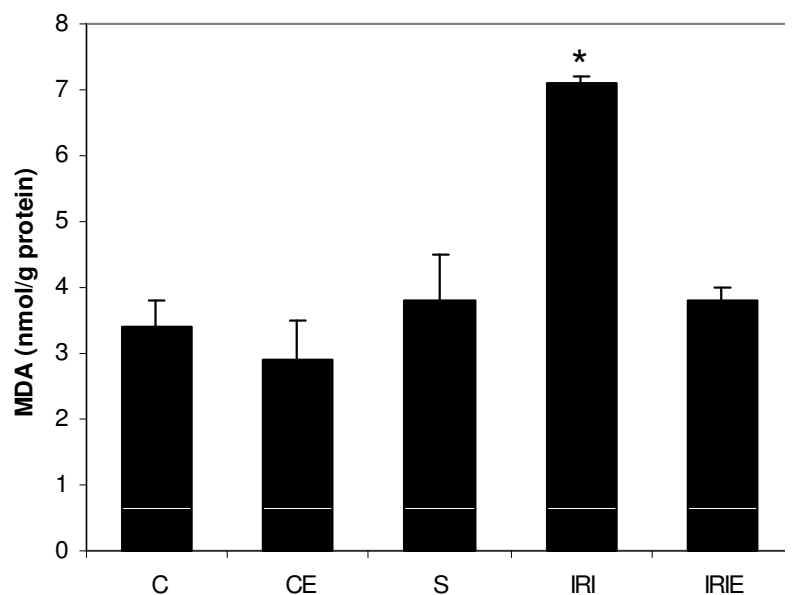

b)

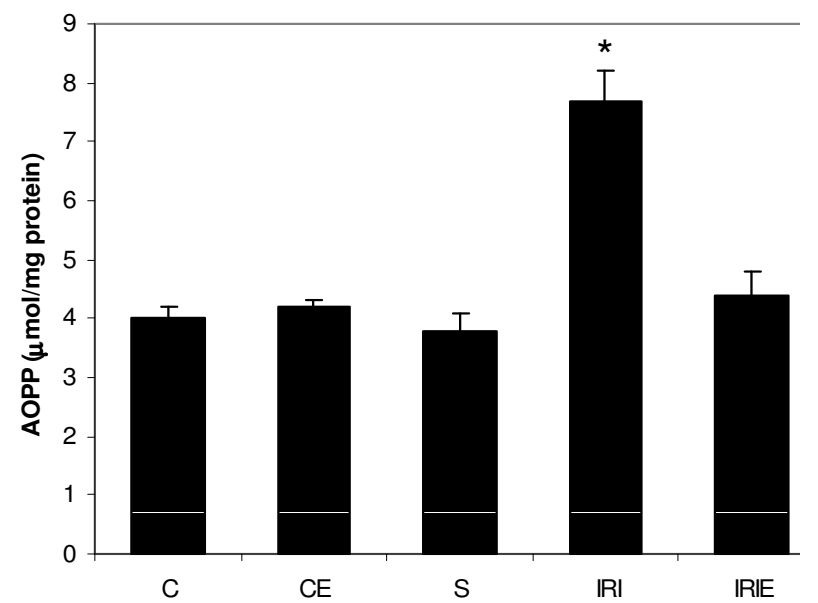

Figure 2 Effect of $\boldsymbol{a}$-Tocopherol treatment for $\mathbf{6}$ weeks in ischemic reperfusion injury in rats. Spinal cord homogenate levels of [a] MDA [b] AOPP. C: Control group; CE: a-Tocopherol control group; S: Sham group; IRI: Ischemic Reperfusion Injury group; IRIE: a-Tocopherol-treated ischemic reperfusion injury group. Results are expressed as mean $\pm S D(n=10)$. The groups which carries the "*" is significantly different from all other groups $(P<0.001)$.

duced recovery of motor and sensory functions $(3.8 \pm 1.0$ and $70 \%$, respectively), while the SPR was recovered in $80 \%$ of IRIE rats (Table 1 ).

\section{Discussion}

Spinal cord injury is usually studied by electrophysiological and histological methods. However, in order to assess the degree of injury and recovery, functional evaluation is crucial [5]. So, the current study was designed on rats with spinal cord reperfusion injury model to evaluate both motor and sensory deficits in addition to other laboratory investigations. Improvement in these deficits was also assessed after $\alpha$-tocopherol administration.

Overproduction of ROS and free radicals is the possible mechanism operating to modulate the patho-physiological phenomenon associated with nervous system injury

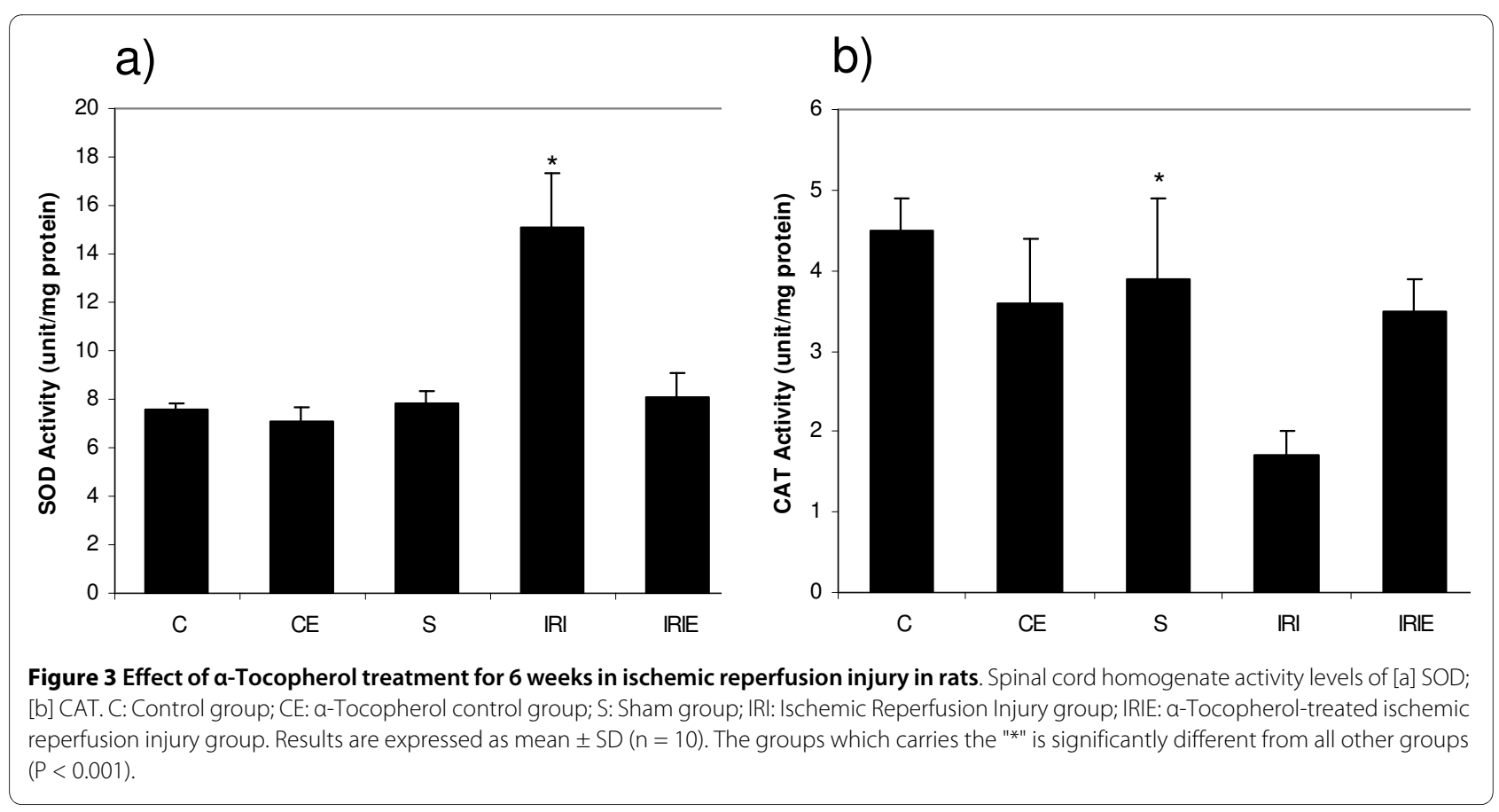


Table 1: Effect of a-Tocopherol treatment in ischemic reperfusion injury model in rats for 6 weeks on Motor function, Sensory response and Placing/Stepping reflex scores

\begin{tabular}{|c|c|c|c|c|c|c|c|}
\hline & Test & $\mathbf{C}$ & CE & $\mathbf{S}$ & IRI & IRIE & p-value \\
\hline Motor assessment & Mean \pm SD & $4.8 \pm 0.4^{(a)}$ & $4.8 \pm 0.4^{(a)}$ & $4.0 \pm 1.1^{(a)}$ & $1.2 \pm 1.0^{(b)}$ & $3.8 \pm 1.0^{(a)}$ & $<0.001$ \\
\hline \multirow[t]{4}{*}{ Sensory assessment } & Normal & 8 & 9 & 7 & 2 & 7 & \\
\hline & & $(80 \%)^{(a)}$ & $(90 \%)^{(a)}$ & $(70 \%)^{(a)}$ & $(20 \%)^{(b)}$ & $(70 \%)^{(a)}$ & \\
\hline & Affected & 2 & 1 & 3 & 8 & 3 & $<0.05$ \\
\hline & & $(20 \%)^{(a)}$ & $(10 \%)^{(a)}$ & $(30 \%)^{(a)}$ & $(80 \%)^{(b)}$ & $(30 \%)^{(a)}$ & \\
\hline \multirow[t]{6}{*}{ Placing/Stepping reflex } & Normal & 8 & 9 & 7 & 2 & 8 & \\
\hline & & & $(90 \%)^{(a)}$ & & & $(80 \%)^{(a)}$ & \\
\hline & Impaired & 2 & 1 & 3 & 2 & 1 & $<0.01$ \\
\hline & & $(20 \%)^{(a)}$ & $(10 \%)^{(a)}$ & $(30 \%)^{(a)}$ & $(20 \%)^{(a)}$ & $(10 \%)^{(a)}$ & \\
\hline & Lost & 0 & 0 & 0 & 6 & 1 & \\
\hline & & $(0 \%)^{(a)}$ & $(0 \%)^{(a)}$ & $(0 \%)^{(a)}$ & $(60 \%)^{(b)}$ & $(10 \%)^{(a)}$ & \\
\hline
\end{tabular}

[33]. The IRI group of rats in our study showed deterioration of motor function and lost placing stepping reflex and impaired sensory function. This finding indicates that induced vascular ischemia resulted in spinal cord injury with subsequent disturbance of different neurological functions [34].

In the present study, spinal cord homogenate MDA levels, as a marker of lipid peroxidation and AOPP levels, as a marker of protein oxidation, increased significantly in the IRI group compared with the control groups (C, CE, $S$ groups with $\mathrm{p}<0.001)$. The same effects have been reported in spinal cord insults induced by chronic constriction injury of the sciatic nerve in rats [6]. The increased generation of oxidative protein product is correlated with the degree of the produced free radicals [35]. Plasma levels of AOPP are also correlated with MDA and pro-inflammatory cytokines levels, suggesting the role of AOPP as a mediator in oxidative stress [36]. Antioxidant enzymes, as SOD, form the primary defense against reactive oxygen metabolites and have been shown to form an important adaptive response to peroxidative stress [37]. In the present study, SOD increased while CAT enzyme decreased significantly in spinal cord homogenate in IRI rats. Similar results have been shown in neurological injuries in series of researches due to oxidative stress and inhibition of antioxidant defense potential [6]. The reduc- tion of CAT activity may be responsible for a number of deleterious effects in IRI due to the accumulation of $\mathrm{H}_{2} \mathrm{O}_{2}$ [38]. Severe reduction of antioxidants levels in nerve, spinal cord and dorsal root ganglion in rat's neurological injuries indicates high susceptibility of these tissues to oxidative stress [6].

Our study demonstrated that $\mathrm{NOx}$ and $\mathrm{PGE}_{2}$ levels increased significantly in the spinal cord homogenate among the IRI group of rats. It was suggested that vascular neurological injuries induce iNOS activity with subsequent $\mathrm{NO}$ over-production leads to COX-2 activation and $\mathrm{PGE}_{2}$ overproduction [39]. Consistent with this, Nogawa et al. [40] found that COX-2 mRNA expression in the brain peaked 12 hours after middle cerebral artery occlusion; at a time when iNOS also reached peak expression as shown by the simultaneous elevation of both NOx and $\mathrm{PGE}_{2}$ in the present work. Transient global ischemia in gerbils results in a biphasic increase in COX activity with an early increase in COX-1 activity and a delayed persistent increase in COX-2 activity with subsequent $\mathrm{PGE}_{2}$ overproduction [41]. It has been documented that COX-2 and its product $\mathrm{PGE}_{2}$ participate in pathogenesis of ischemic injury in the human brain [42].

Our results showed reduction of the lipid peroxidation product "MDA", protein oxidation product "AOPP" and 
plasma NOx levels in the IRIE group, compared with the control groups. Ziegler et al. stated that $\alpha$-TOL is one of the most potent biological antioxidants in the body tissues that effectively protects against neuronal oxidative stress damage. It interacts with free radicals and prevents lipid peroxidation [43]. Clinically, $\alpha$-TOL supplementation led to electrophysiological recovery of sensory conduction and evoked potentials in neurological vascular insults [44]. Experimental studies showed that $\alpha$-TOL administration in animal's ischemic reperfusion injury not only attenuates the oxidative injury of the muscle cells but also reduces the formation of edema in these cells. This may be due to the anti-inflammatory effect of $\alpha$-TOL by inhibiting $\mathrm{PGE}_{2}$ production [43]. The inhibitory effect of $\alpha$-TOL on $\mathrm{PGE}_{2}$ production in the presence of abundant arachidonic acid, (the substrate for $\mathrm{PGE}_{2}$ ), indicates that $\alpha$-TOL mediates $\mathrm{PGE}_{2}$ inhibition mainly through COX-2 inhibition rather than through substrate release [45]. Wu et al. [46] showed that $\alpha$-TOL exerts its effect on COX activity and not on the downstream enzyme $\mathrm{PGE}_{2}$ isomerase activity. They investigated the effect of $\alpha$-TOL on another COX product, thromboxane $\mathrm{A}_{2}$ in the supernatant from COX activity cultures and they did not find any effect of $\alpha$-TOL on the isomerase activity. As full activation of COX-2 enzyme requires the presence of sufficient hydroperoxides [10]; $\alpha$-TOL might attenuate COX-2 activity by scavenging the oxidant hydroperoxide and reducing the formation of peroxynitrite [18]. The fact that $\alpha$-TOL inhibits COX-2 activity in old mice supports this finding, as formation of lipid peroxides and NO increases in different tissues of the aged animals [18]. Some investigators reported that NO stimulates COX activity via direct stimulation of the enzyme [47]. It is metabolized to peroxynitrite (ONOO) in the presence of superoxide with subsequent induction of COX activity without affecting its expression. $\alpha$-TOL may acts via other mechanisms than antioxidant activity including cell signaling, interfering with other enzymatic activity, apoptosis and modulating gene expression that may contribute to its neuroprotective action [48].

Administration of $\alpha$-TOL in IRI rats not only improves the biochemical parameters measured but almost restores the motor function, placing steeping reflex and sensory responses to noxious stimuli up to the normal control levels. This confirms that $\alpha$-TOL not only improves all aspects of oxidative stress injury and inflammatory responses of the spinal cord in IRI but also its clinical neurological impacts [14]. Interruption of aortic blood flow in IRI may not only induce spinal cord injury, but also induce injury of the heart, gut, and kidney [41]. An additional mechanism that could be responsible for $\alpha$ TOL long-lasting neuro-protection of neurons against oxidative stress; this was reported by Crouzin et al. who found that, oxidative stress insults activates transient receptor potential vanilloid 1 (TRPV1) channels which one of the members of transient receptor potential (TRP) family in neuronal tissues. Activation of these channels mediate exaggerated $\mathrm{Ca}^{2+}$ influx with subsequent neuronal death. $\alpha$-TOL pretreatment in oxidative stress conditions down-regulates TRPV1 channels activity [49]. In addition, it has been found that the tocotrienol (TCT), the subfamily of natural vitamin E, possesses powerful neuroprotective activity. Nanomolar TCT significantly attenuates the effects of glutamate on fatty acid levels and on cytosolic phospholipase $\mathrm{A}_{2}$. Phospholipase $\mathrm{A}_{2}$ activation results in the release of free arachidonic acid within the cell. Through the Src-Lox death pathway, arachidonic acid overproduction results in the formation of 12hydroperoxyeicosatetraenoic acid which is lethal for cells [50]. While our data showed a neuro-protective effect of $\alpha-\mathrm{TOL}$ in reducing the incidence of paraplegia, it may exert further protective effects on other organs. So, more investigations are required to prove or disprove this hypothesis.

In conclusion, i.m. administration of the COX-2 inhibitor $\alpha$-TOL, at a dose of $600 \mathrm{mg}$ twice weekly for six weeks, significantly prevents the damage caused by spinal cord ischemia in rats. Moreover, $\alpha$-TOL improves motor and sensory functions and reduces oxidative stress level. Because spinal cord ischemia-induced paraplegia remains a serious complication of IRI, prophylactic $\alpha$-TOL administration might prove useful in its prevention. However, extrapolating from rats to humans in this entity must be done with caution, and testing with different doses and therapy regimens in some other animal species remains to be completed and thoroughly observed by safety trials in humans before its clinical use.

\section{Competing interests}

The authors declare that they have no competing interests.

\section{Authors' contributions}

MMD participated in the design of the study, performing of the experiments and helping draft the manuscript. OAM participated in the performing the experiment and revised the manuscript and constructed the figures and tables. WNH performed the chemical analysis and participated in revision of the manuscript including figures and tables. All authors have read carefully and approved the final manuscript.

\section{Acknowledgements}

Thanks to all staff members and technicians of the physiology Lab of Collage of Medicine, Menoufiya University, Egypt for their great help in every step in this work.

\section{Author Details}

1Physiology Department, College of Medicine, Menoufiya University, Egypt, 2Public Health Department, College of Medicine, Beni Suef University, Eygpt and ${ }^{3}$ Biochemistry Department, College of Medicine, Menoufiya University, Egypt

Received: 15 April 2010 Accepted: 7 July 2010 Published: 7 July 2010 


\section{References}

1. Wang JY, Shen J, Gao Q, Ye ZG, Yang SY, Liang HW, Bruce IC, Luo BY, Xia Q: Ischemic Postconditioning Protects Against Global Cerebral Ischemia/ Reperfusion-Induced Injury in Rats. Stroke 2008, 39(3):983-990.

2. Crawford ES, Caselli JS: Thoracoabdominal aneurysm surgery. Semin Thorac Cardiovasc Surg 1991, 3:300-322.

3. Xing B, Chen H, Zhang M, Zhao D, Jiang R, Liu X, Zhang S: Ischemic Postconditioning Inhibits Apoptosis After Focal Cerebrallschemia/ Reperfusion Injury in the Rat. Stroke 2008, 39:2362-2369.

4. Park ES, Gao X, Chung JM, Chung K: Levels of mitochondrial reactive oxygen species increase in rat neuropathic spinal dorsal horn neurons. Neurosci Lett 2006, 391:108-111.

5. Varija D, Kumar K, Reddy K, Reddy V: Prolonged constriction of sciatic nerve affecting oxidative stressors and antioxidant enzymes in rat. Indian J Med Res 2009, 129:587-592.

6. Naik AK, Tandan SK, Dudhgaonkar SP, Jadhav SH, Kataria M, Prakash VR, Kumar D: Role of oxidative stress in pathophysiology of peripheral neuropathy and modulation by $\mathrm{N}$-acetyl-L-cysteine in rats. Eur J Pain 2006, 10:573-579.

7. Regan RF, Guo Y: Magnesium deprivation decreases cellular reduced glutathione and causes oxidative neuronal death in murine cortical cultures. Brain Res 2001, 890:177-183.

8. Yamagata K, Andreasson Kl, Kaufmann WE, Barnes CA, Worley PF: Expression of a mitogen-inducible cyclooxygenase in brain neurons: regulation by synaptic activity and glucocorticoids. Neuron 1993 11:371-386.

9. Candelario-Jalil E, Fiebich BL: Cyclo-oxygenase inhibition in ischemic brain injury. Curr Pharma Des 2008, 14(14):1401-1418.

10. Kulmacz RJ, Wang LH: Comparison of hydroperoxide initiator requirements for the cyclooxygenase activities of prostaglandin $\mathrm{H}$ synthase-1 and -2. J Biol Chem 1995, 270(41):24019-24023.

11. Lacroix S, Rivest S: Effect of acute systemic inflammatory response and cytokines on the transcription of the genes encoding cyclooxygenase enzymes (COX-1 and COX-2) in the rat brain. J Neurochem 1998, 70:452-466.

12. Nakayama M, Uchimura K, Zhu RL, Nagayama T, Rose ME, Stetler RA, Isakson PC, Chen J, Graham SH: Cyclooxygenase-2 inhibition prevents delayed death of CA1 hippocampal neurons following global ischemia. Proc Natl Acad Sci USA 1998, 95:10954-10959.

13. Nagayama M, Niwa K, Nagayama T, Ross ME, ladecola C: The cyclooxygenase-2 inhibitor NS-398 ameliorates ischemic brain injury in wild-type mice but not in mice with deletion of the inducible nitric oxide synthase gene. J Cereb Blood Flow Metab 1999, 19:1213-1219.

14. Reed A, Cho YJ, Coombes JS, Fassett RG: Time course and dose response of alpha tocopherol on oxidative stress in haemodialysis patients. BMC Nephrology 2009, 22:10-32.

15. Haidara MA, Mikhailidis DP, Rateb MA, Ahmed ZA, Yassin HZ, Ibrahim IM Rashed $L A$ : Evaluation of the effect of oxidative stress and vitamin $E$ supplementation on renal function in rats with streptozotocin-induced Type 1 diabetes. J Diabetes Complications 2008, 23(2):130-136.

16. Devaraj S, Tang R, Adams-Huet B, Harris A, Seenivasan T, de Lemos JA, Jialal I: Effect of high-dose alpha-tocopherol supplementation on biomarkers of oxidative stress and inflammation and carotid atherosclerosis in patients with coronary artery disease. Am J Clin Nutr 2007, 86:1392-1398.

17. Lee E, Choi M, Lee Y, Ku J, Kim K, Choi J, Lim S: Alpha-tocopherol succinate, in contrast to alpha-tocopherol and alpha-tocopherol acetate, inhibits prostaglandin E2 production in human lung epithelial cells. Carcinogenesis 2006, 27(11):2308-2315

18. Wu D, Hayek M, Meydani S: Vitamin E and Macrophage Cyclooxygenase Regulation in the Aged. Journal of Nutrition 2001, 131:382S-388S

19. Hajiani M, Golestani A, Shariftabrizi A, Rastegar R, Payabvash S, Salmasi AH, Dehpour AR, Pasalar P: Dose-dependent modulation of systemic lipid peroxidation and activity of anti-oxidant enzymes by vitamin $\mathrm{E}$ in the rat. Redox Rep 2008, 13(2):60-6.

20. Akguna S, Tekelia A, Kurtkayab O, Civeleka A, Isbira S, Aka K, Arsanc S, Savb A: Neuroprotective effects of FK-506, L-carnitine and azathioprine on spinal cord ischemia-reperfusion injury. European Journal of Cardiothoracic Surgery 2004, 25:105-110.

21. Taira Y, Marsala M: Effect of proximal arterial perfusion pressure on function, spinal cord blood flow, and histopathological changes after increasing intervals of aortic occlusion in the rat. Stroke 1996 27:1850-1858.

22. Damiani CE, Rossoni LV, Vassallo DV: Vasorelaxant effects of eugenol on rat thoracic aorta. Vascular Pharmacology 2003, 40:59-66.

23. Tarlov IM: Acute spinal cord compression paralysis. J Neurosurg 1972 36:10-20.

24. Marsala M, Yaksh TL: Transient spinal ischemia in the rat: characterization of behavioral and histopathological consequences as a function of the duration of aortic occlusion. J Cereb Blood Flow Metab 1994, 14:526-535

25. Green LC, Tannenbaum SR, Goldman P: Nitrate synthesis in the germfree and conventional rat. Science 1981, 212:56-58

26. Zvara DA, Andrew JB, Deal DD, DeMarco MP, Campos KM, Mansfield CM, Tytell M: Anesthetic Preconditioning with Sevoflurane Does Not Protect the Spinal Cord After an Ischemic-Reperfusion Injury in the Rat. Anesth Analg 2006, 102:1341-1347.

27. Templar J, Kon SP, Milligan TP, Newman DJ, Raftery MJ: Increased plasma malondialdehyde levels in glomerular disease as determined by a fully validated HPLC method. Nephrol Dial Transplant 1999, 14:946-945.

28. Ohkawa $\mathrm{H}$, Ohishi N, Yagi K: Assay for lipid peroxides in animal tissues by thiobarbituric acid reaction. Anal Biochem 1979, 95:351-358.

29. Kalousova M, Skrha J, Zima T: Advanced glycation endproducts and advanced oxidation protein products in patients with diabetes mellitus. Physiol Res 2002, 51:597-604.

30. Kakkar P, Das B, Viswanathan PN: A modified spectrophotometric assay of superoxide dismutase. Indian J Biochem Biophys 1984, 21:130-132.

31. Bonaventura J, Schroeder WA, Fang S: Human erythrocyte catalase: an improved method of isolation and revaluation of reported properties. Arch Biochem Biophys 1972, 150:606-617.

32. Zhao P, Stephen G, Waxman SG, Hains BC: Neurobiology of Disease Extracellular Signal-Regulated Kinase Regulated Microglia-Neuron Signaling by Prostaglandin E2 Contributes to Pain after Spinal Cord Injury. Journal of Neuroscience 2007, 27(9):2357-2368.

33. Genestra M: Oxyl radicals, redox-sensitive signalling cascades and antioxidants. Cell Signal 2007, 19:1807-1819.

34. Tang J, Hua Y, Su J, Zhang P, Zhu X, Wu L, Niu Q, Xiao H, Ding X: Expression of VEGF and neural repair after alprostadil treatment in a rat model of sciatic nerve crush injury. Neurol India 2009, 57(4):387-394.

35. Skvarilova M, Bulava A, Stejskal D, Admovska S, Bartek J: Increased level of advanced oxidation products (AOPP) as a marker of oxidative stress in patients with acute coronary syndrome. Bio Med Papers 2005, 149:83-87.

36. Pekarkova I, Parara S, Holecek V, Stopka P, Trefil L, Racek J, Rokyta R: Does exogenous melatonin infl uence free radicle metabolism and pain sensation in rats? Physiol Res 2001, 50:595-602.

37. Sgaravatti AM, Magnusson AS, Oliveira AS, Mescka CP, Zanin F, Sgarbi MB, Pederzolli CD, Wyse AT, Wannmacher CM, Wajner M, Dutra-Filho CS: Effects of 1,4-butanediol administration on oxidative stress in rat brain: study of the neurotoxicity of gamma-hydroxybutyric acid in vivo. Metab Brain Dis 2009, 24(2):271-82

38. Struzyńska L, Chalimoniuk M, Sulkowski G: The role of astroglia in Pbexposed adult rat brain with respect to glutamate toxicity. Toxicology 2005, 212(2-3):185-194.

39. Genovese T, Rossi A, Mazzon E, Di Paola R, Muià C, Caminiti R, Bramanti P, Sautebin L, Cuzzocrea S: Effects of zileuton and montelukast in mouse experimental spinal cord injury. Br J Pharmacol 2008, 153(3):568-582.

40. Nogawa S, Forster C, Zhang F, Nagayama M, Ross ME, ladecola C: Interaction between inducible nitric oxide synthase and cyclooxygenase-2 after cerebral ischemia. Proc Natl Acad Sci USA 1998 95:10966-10971.

41. Hsieh Y, Liang W, Tsai S, Wong C: Intrathecal Ketorolac Pretreatment Reduced Spinal Cord Ischemic Injury in Rats. Anesth Analg 2005, 100:1134-1139.

42. Jadhav V, Ostrowski RP, Tong W, Matus B, Jesunathadas R, Zhang JH: Cyclo-oxygenase-2 mediates hyperbaric oxygen preconditioning induced neuroprotection in the mouse model of surgical brain injury. Stroke 2009, 40(9):3139-3142.

43. Silva MG, Castro AA, Ramos EA, Peixoto E, Miranda F, Pitta GB, Costa RF, Juliano Y: Histological and biochemical serum effects of alphatocopherol on ischemia/reperfusion-related injuries induced in the pelvic limb of the rat. Acta Cirurgica Brasileira 2005, 20:375-381. 
44. Puri V, Chaudhry N, Tatke M, Prakash V: Vitamin E deficiency with demyelinating neuropathy. Isolated Muscle Nerve 2005, 32:230-235.

45. Wu D, Liu L, Meydani M, Meydani S: Vitamin E Increases Production of Vasodilator Prostanoids in Human Aortic Endothelial Cells through Opposing Effects on Cyclooxygenase-2 and Phospholipase A2. J Nutr 2005, 135:1847-1853.

46. Wu D, Mura C, Beharka A, Han S, Paulson KE, Hwang D, Meydani S: Ageassociated increase in $\mathrm{PGE}_{2}$ synthesis and $\mathrm{COX}$ activity in murine macrophages is reversed by vitamin E. Am J Physiol Cell Physiol 1998 , 275(3):C661-C668.

47. Lin YS, Hung SC, Wei YH, Tarng DC: GST M1 polymorphism associates with DNA oxidative damage and mortality among hemodialysis patients. J Am Soc Nephrol 2009, 20(2):405-15.

48. Jiang Q, Elson-Schwab I, Courtemanche C, Ames BN: Gamma-tocopherol and its major metabolite, in contrast to alpha-tocopherol, inhibit cyclooxygenase activity in macrophages and epithelial cells. Proc Natl Acad Sci USA 2000, 97:11494-11499.

49. Crouzin N, Ferreira MC, Cohen-Solal C, Barbanel G, Guiramand J, Vignes M: Neuroprotection induced by vitamin E against oxidative stress in hippocampal neurons:involvement of TRPV1 channels. Mol Nutr Food Res 2010, 54(4):496-505.

50. Khanna S, Parinandi NL, Kotha SR, Roy S, Rink C, Bibus D, Sen CK. Nanomolar vitamin E alpha-tocotrienol inhibits glutamate-induced activation of phospholipase A2 and causes neuroprotection. J Neurochem 2010, 112(5):1249-1260.

doi: 10.1186/1423-0127-17-55

Cite this article as: Morsy et al., A potential protective effect of ?-tocopherol on vascular complication in spinal cord reperfusion injury in rats Journal of Biomedical Science 2010, 17:55

Submit your next manuscript to BioMed Central and take full advantage of:

- Convenient online submission

- Thorough peer review

- No space constraints or color figure charges

- Immediate publication on acceptance

- Inclusion in PubMed, CAS, Scopus and Google Scholar

- Research which is freely available for redistribution

Submit your manuscript at www.biomedcentral.com/submit
Ciomed Central 